\title{
A INFLUÊNCIA DO PROBLEMA DE PRECARIZAÇÃO NO TRABALHO NA RELAÇÃO ENTRE O GRUPO DE APOIADORES E O MODELO DE GESTÃO DE UMA COOPERATIVA DE RECICLAGEM DE RESÍDUOS SÓLIDOS
}

\section{Wilson Roberto Lussari ${ }^{1}$}

Antônio Cezar Leal ${ }^{2}$

Edilene Mayumi Murashita Takenaka ${ }^{3}$

RESUMO: Ao buscarmos uma compreensão sobre o rumo que uma organização cooperativa adota, perseguimos uma identificação de como ela é orquestrada e por quem ela é orquestrada. A fim de contextualizar tal organização abordamos alguns pontos pertinentes: sociedade, exclusão, lixo e precarização do trabalho. $O$ presente trabalho procura evidenciar a influência da precarização do trabalho no contexto da relação entre um grupo de apoiadores junto a uma cooperativa de trabalhadores em materiais recicláveis nas dimensões política, assistencial, educacional, cultural e econômica. Para tanto, o presente trabalho considerou a necessidade dos pesquisadores envolvidos em buscar uma compreensão particular do tema estudado fazendo uso da abordagem qualitativa e também na observação participante, tendo obras de diversos autores como referencial bibliográfico que permitiram o contato com questões existentes e explorar novos conhecimentos sobre o assunto tratado.

Palavras-chave: Educação Ambiental. Precarização. Trabalho.

\footnotetext{
${ }^{1}$ Mestre em Educação - Aluno regular do Programa de Pós-Graduação em Geografia da FCT/UNESP de Presidente Prudente-SP. (wlussari@unoeste.br)

${ }^{2}$ Doutor em Geografia - Docente do Programa de Pós-Graduação em Geografia da FCT/UNESP de Presidente Prudente-SP (cezar@fct.unesp.br)

${ }^{3}$ Doutora em Geografia - Unesp, Docente do Mestrado em Meio Ambiente e Desenvolvimento Regional da Unoeste (edilene@unoeste.br)
} 


\section{INTRODUÇÃO}

Construir as relações de uma sociedade vai muito além de uma simples identificação delas e descrevê-las em termos das interações entre indivíduos. O ser humano, pela sua própria natureza, está constantemente se deslocando tanto no tempo como no espaço. Aliado à vertiginosa evolução da sociedade, em termos materiais, ao longo do tempo, continua a sua lenta evolução psicossocial. De um lado, bolsões de sociedade altamente evoluídos, ao mesmo tempo em que em outro ponto do planeta, ou até mesmo do outro lado da cidade, encontramos sociedades completamente numa condição subumana, digna da pré-história.

Entretanto, ao analisarmos mais detidamente mesmo estas sociedades mais prósperas, notamos que elas também têm seus próprios bolsões de miséria. Tais bolsões acabam sendo minimizados, ignorados mesmo, dadas suas características, as quais destoam do sonho ou do desejo de felicidades das pessoas. Mas são seres humanos os quais, por diferentes motivos acabaram ficando a reboque da sociedade, buscando sua sobrevivência em atividades muitas vezes degradantes ou humilhantes, que o nivela por baixo de uma escala de submundo humano.

Tal situação ainda pode ser focada ainda mais especificamente, ao nível de uma organização. Aqui temos uma estrutura social, naturalmente em castas, dada sua necessidade de se submeter ao processo produtivo, onde há a necessidade de diferentes tipos ações, bem como de diferentes habilidades humanas. Comumente elas se desdobram em classificações, que buscam estabelecer um statu quo em termos de importância ou ordenamento.

Nas organizações temos o espaço geográfico do trabalho, bem como os elementos de segregação e distinção entre os mais e os menos importantes nelas. Tais aspectos provocam uma natural distribuição das pessoas na organização, bem como se estabelece as bases das relações sociais de grupos.

No processo capitalista de produção, estas características são evidenciadas pelas empresas, cujos propósitos econômicos acabam ditando naturalmente esta discriminação. 
Paralelamente, este processo é aceito e legitimado pelos integrantes, uma vez que eles foram nascidos e criados neste sistema.

Assim, o individuo acaba se estabelecendo como o responsável pelo seu próprio destino, carreado pelas circunstancias de sua própria vida. Dependendo de suas escolhas ele acaba perdendo sua identidade e sua relação com uma sociedade estruturada em organizações. Neste ponto cabe estabelecer a questão de vivermos em uma sociedade em organizações.

Para que possamos estabelecer uma perspectiva sobre o presente artigo, necessitamos abordar alguns pontos pertinentes: sociedade, exclusão, lixo e precarização do trabalho.

O objeto de referência é uma cooperativa de trabalhadores em material reciclável de Presidente Prudente-SP, a COOPERLIX, que surgiu como resultado do esforço conjunto entre os diversos setores da sociedade, envolvidos no Projeto de Políticas Públicas/FAPESP e financiado pela FAPESP.

\section{DE CATADOR A COOPERADO: A PERSISTÊNCIA DA PRECARIZAÇÃO}

Uma vez que vivemos em uma sociedade de organizações, acabamos por ser afetados em nossa vida em representar um papel para cada organização que nos correlacionamos. Quanto mais organizações, mais papéis e isso implica em nos despersonalizarmos, pois o humano acaba sendo colocado em um plano secundário, a fim de que possamos sobreviver dependentes de uma dada organização (ou de várias).

$\mathrm{Na}$ presente segunda década do século XXI estamos experimentando uma sociedade cada vez mais conectada e ao mesmo tempo, cada vez mais fragmentada em grupos. A emergência da sociedade hiperconectada acabou criando um novo processo de exclusão: os analfabetos digitais (Gilster, 1997). Porem não eliminou os outros tipos de exclusão, levando os mais desfavorecidos ainda mais para o limbo da sociedade. Neste século, a humanidade tem um grande desafio, que é rever sua história e fazer um balanço sobre sua evolução. Paralelamente o capitalismo tem se metamorfoseado em uma nova perspectiva, pós-industrial, caracterizada pela era da informação. 
Se pelo lado da visão da sociedade temos muito a comemorar quanto às melhores condições de vida, derivada dos avanços tecnológicos, especialmente no século XX, as desigualdades sociais só aumentaram, sobretudo nos últimos 30 anos. Tal desigualdade, aparentemente percebida nos países pobres, também tem se acentuado nos países ricos, por diversos motivos. Kotkin (2001) aponta que apesar de passar por um dos mais robustos períodos econômicos dos Estados Unidos, a disparidade social entre classes aumentou.

Historicamente a sociedade sempre esteve vinculada à sua maior manifestação humana: a cidade. Kotkin (2005) sustenta que a cidade é a universalidade da experiência urbana, apesar da vasta diferença de raças, clima e localização. Isto é verdade mesmo antes da comunicação instantânea, redes globais e facilidade de transportes que fizeram das semelhanças das cidades ainda mais óbvias. Uma segunda generalização sobre o que caracteriza as cidades de sucesso, segundo Kotkin (2005), é que, desde suas origens, as áreas urbanas desempenharam três funções críticas distintas: a criação de espaço sagrado, a provisão de segurança básica e a oferta de um espaço para o comércio.

Ao promovermos uma leitura da sociedade, não podemos ignorar que ela está em constante mutação ou evolução. Neste particular, Kotkin (2001) aponta que no século XXI, e mesmo além, as comunidades podem apenas sobreviver e prosperar sendo algo mais do que códigos postais desalmados de tijolos e vidros interconectados por cabos de fibra ótica. E elas podem ser ainda mais, apenas fomentando um senso de conectividade - em união humana, não apenas links eletrônicos - entre várias comunidades, negócios e imediações. Mais que qualquer coisa, este senso reclamado de espírito cívico, não tecnologia ou intervenção governamental, determinará como as comunidades do futuro garantirão lugar na geografia da era digital.

Sempre com uma visão mais otimista e perceptiva sobre caminho trilhado pela sociedade, e apesar da crise econômica de 2008, Kotkin (2010) posicionou-se no ponto de vista da cidade do futuro: Estes artesãos da era pós-industrial - junto com os trabalhadores de classe média mais tradicional, tais como servidores, professores e enfermeiros - podem prover da base residencial crítica para as vizinhanças urbanas mais comuns. Nem pobres nem ricos, estes artesãos podem utilizar as novas redes de telecomunicações para 
acessar clientes nos grupos suburbanos alastrados, através dos Estados Unidos ou no exterior.

A cidade sustentável em 2050 comenta Kotkin (2010), dependerá em grande parte da revitalização de instituições tradicionais que tenham se desvanecido em muitas cidades de hoje.

Voltando à realidade corrente, percebemos que a transformação humana para uma sociedade melhor sempre deixa um número expressivo de pessoas para trás. Em parte este processo deriva do sistema de produção capitalista, ao qual todos nós estamos inseridos, mas também das próprias condições de desenvolvimento local e regional.

Quando procedemos a uma reflexão acerca do papel do homem em sociedade, percebemos que ele busca com seu semelhante construir uma vida mais digna e uma sociedade melhor. À medida que procedemos a um aprofundamento nesta reflexão, compreendemos que ao longo da história, há uma constante luta entre o desejo de melhorar a condição do ser humano e a real conquista para ele. Isto se deve em parte do conflito de expectativas entre as pessoas e das formas de se atingir tais expectativas.

Uma referência ao problema da formação de uma massa de mão de obra historicamente expropriada de suas origens e a acumulação primitiva de capitais. No que tange à acumulação primitiva, a história remonta a um tempo longínquo. (Marx, 1958)

Tal como na antiguidade, a Idade Média também teve seu papel neste processo, em particular na Inglaterra, conforme cita Marx, os sucessivos processos de expropriação. "Na Inglaterra, a servidão desaparecera, de fato, por volta do fim do século XIV. A imensa maioria da população compunha-se, então, mais ainda no século $X V$, de camponeses livres e proprietários [...]" (idem, 148).

No século XVIII, a lei sobre o fechamento das terras comunais e outras medidas, despeja ainda mais indivíduos no mercado de indigentes. No século XIX, perdeu-se, naturalmente, até a lembrança do laço que unira o agricultor à propriedade comunal. Com mais de três séculos de expropriações, o crescimento deste proletariado sem eira nem beira caminhou necessariamente mais depressa do que a sua absorção pelas manufaturas nascentes (Marx, 1958).

Para nossa reflexão, temos então uma bifurcação do entender quanto ao termo artesão. Uma vez que no início da Revolução Industrial, na Inglaterra, havia um elevado 
número de indivíduos que migraram para as cidades, muitos dos quais expulsos de suas origens ou em busca de oportunidade de sobrevivência, a disponibilidade de mão de obra em abundancia abrigava diferentes artífices.

De um lado aqueles que tinham habilidades e, eventualmente, seus instrumentos de trabalho, que eram úteis em qualquer comunidade, urbana ou rural, grande ou pequena. Por outro, e por sinal mais numeroso, um volume expressivo de camponeses e artesãos, os quais Ihes haviam tirado o elemento fundamental que era a terra, como fonte de subsistência e / ou exploração, sem a qual de nada adiantava ter as ferramentas. Curiosamente uma mesma realidade que viríamos a ter alguns séculos depois, no fim do capitalismo industrial.

Desta forma, tal como hoje, havia uma miríade de artesãos disponíveis no mercado, potencialmente úteis para trabalhar nas manufaturas. Assim, havia os que tinham as mesmas (ou nenhuma) habilidades, em abundância; outros, em menor número, com habilidades imprescindíveis, que poderiam estabelecer suas bases de negociação; e um terceiro tipo de artesão, que estava por surgir, precursor da futura classe médio operária, formado dentro das próprias fábricas, dada sua inexistência.

No âmbito do processo de transformação social dos últimos 200 anos, percebeu-se uma polarização entre os que se beneficiavam de fato da prosperidade da humanidade e os que bancavam esta prosperidade à custa de seu presente e futuro, e de seus descendentes. Apesar da exploração do homem pelo homem ser antiga, foi a partir da Revolução Industrial que ele se acirrou e se institucionalizou, migrando de um modelo de escravização do homem, pela escravização do trabalho.

No Brasil, este movimento ocorreu praticamente ao longo do século $X X$, visto que até a década de 1950 era um país tipicamente agrícola. O processo de migração para uma sociedade industrial levou um pouco mais de tempo, frente aos países europeus, por exemplo, apesar de que a industrialização ter se iniciado em fins do século XIX, porém apenas após a Segunda Guerra Mundial que o Brasil se consolidou como uma sociedade industrial de fato.

Os países que melhor aproveitaram as oportunidades nos anos 1960s e 70s emergiriam na década de 90 com o rótulo de países emergentes. Essencialmente estava em jogo a inserção do país no rol de países industrializados, bem como a formação de 
uma elite profissional trabalhadora (particularmente urbana) necessária para permitir a agregação de valor aos produtos exportáveis. A rápida transformação de economia agrícola em economia industrializada, iniciada na década de 1950, e da transformação de uma economia industrial para economia de serviços no começo do século XXI (com participação de 54\% do PIB), faz do Brasil um exemplo deste fenômeno.

A fim de estabelecer a figura do trabalhador neste cenário, torna-se necessário contextualizar brevemente uma relação entre desemprego, mercado de trabalho e a essência da irracionalidade sistêmica do capital. Antes de mais nada, precisamos situar os pontos desta questão. Quando pensamos em desemprego, temos em um primeiro momento aqueles que não possuem trabalho remunerado com carteira assinada. Porém, dado o avanço da precarização do trabalho, outras formas também passaram a engrossar a parcela de empregados. Desta forma temos que os assalariados de fato sofram um esmagamento de sua força mediante forças traduzidas como flexibilização e desregulamentação (Vasapollo, 2006).

$\mathrm{Na}$ essência a flexibilização veio para combater o desemprego, entretanto, ela acabou sendo "uma imposição à força de trabalho para que sejam aceitos salários reais mais baixos e em piores condições".

Dentro desta linha de pensamento, percebemos que o desemprego por si é um estado daquela parte da sociedade que apesar de ter alguma qualificação para trabalhar, esteja impossibilitada de tal, pois faz parte da reserva de trabalho do capital.

Por extensão, tal como Antunes (1999) cita, aquela massa de "excluídos", caracterizada por desemprego estrutural, reflete a lógica destrutiva do metabolismo societal, presente na massa dos excluídos do trabalho vivo. Esta situação reflete bem o dilema de se caracterizar o desemprego, visto que podemos dar a forma que desejarmos, pois, independente dela, o capital delimita a massa de trabalho vivo necessária para suas necessidades.

Decorrente deste ponto, entendemos que o capital em sua evolução aos poucos foi se apropriando de todos os elementos presentes na sociedade para perpetuar sua condição. Apesar da apregoada crise do capitalismo, na verdade ela apenas ilustrava um momento em que o capital se modificava, agregando uma nova forma de reduzir o trabalho vivo e aumentar o trabalho morto (Antunes, 1999). 
Ao absorver os avanços tecnológicos nos últimos 40 anos, procedeu-se uma significativa redução do trabalho vivo, mediante implantação de processos de produção que ampliavam o trabalho morto. Este movimento implicou em uma sensível mudança na qualificação da mão de obra, reduzindo assim a quantidade de força necessária ao metabolismo do capital. Aqueles não requalificados que foram excluídos do processo engrossavam o desemprego estrutural, bem como os que eventualmente fossem qualificados aumentavam as estatísticas dos desempregados.

Em relação ao mercado de trabalho, esta transição do modelo fordista para o toyotista, foi além de uma troca de técnica. Houve uma ruptura do modelo de produção e, por conseguinte, do processo de apropriação do trabalho vivo em trabalho morto. Para o ser humano, esta transformação levou a um esgotamento de suas possibilidades de produção de mais valia, beirando a escravidão, uma vez que exclui uma parcela significativa da população, empurrando-a para as "esferas isoladas do não-trabalho (atividade de formação, de benevolência e de serviços)" (Tosel apud Antunes, 1999).

Assim, "aumentam os focos de contradição entre os desempregados e a sociedade como um todo, entre a 'racionalidade' no âmbito produtivo e a 'irracionalidade' no universo societal. Os conflitos tornam-se um problema social, mais do que uma questão empresarial, transcendendo o âmbito fabril e atingindo o espaço público e societal” (Antunes, 1999).

É interessante a reflexão, quando o capitalismo, enquanto diminui a participação do trabalho vivo, porém sem o eliminar, provoca o alijamento de um contingente de pessoas que não tem a menor possibilidade de consumir, excluindo as potenciais fontes de lucro. Levando uma vida sem sentido, o ser humano que não pode trabalhar nem consumir, busca uma manifestação de revolta, para sair deste estranhamento, frequentemente interpretado como revolução, subversão e outros tipos de movimentos que apenas procuram uma saída, como se fosse a válvula de uma panela de pressão.

Tal como Antunes cita no texto, ontem foi Los Angeles (1992) e França (1997), hoje temos os países árabes. O dilema continuará por muito tempo.

O problema é que não há trabalho para todos, agravado pela questão da flutuação das demandas de mercado. Assim, ainda há uma parcela da sociedade encurralada na periferia da cidade (para não dizer marginalidade), sem chance alguma de trabalho, seja 
por não ser "apta" ao trabalho, seja por estar fora como "mercadoria no mercado", já que nem sempre tem a formação formal mínima exigida por esta mesma sociedade.

Um aspecto que tem evidenciado o agravamento desta condição foi a emergência dos movimentos sociais organizados. Um exemplo podemos tomar no Pontal, percebeu-se que o alijamento do indivíduo do campo, produziu uma situação que o coloca no limbo da sociedade, que o sequer considerava como identidade. Sem posse, sem terra, sem capacidade ao trabalho urbano, além de sem perspectiva de futuro a si e seus filhos, acabou impelido ao confrontar a própria sociedade, não com a intenção de se tornar um criminoso, mas como alguém que luta para ser reconhecido como cidadão dentro desta mesma sociedade.

A resposta foi buscar a sua identidade a partir do ponto em que a perdeu, na transição do campo para a cidade. Ali, o que era antes seu espaço de trabalho e de identidade social, também perdera sua identidade. O que sobrou foram terras que um dia havia alguém que as explorava, porem não tinha a devida posse legal. Substituído por outros que também não tinham a posse legal, ficava uma indagação: como resgatar a identidade a partir do ponto em que a perdera, uma vez que não era reconhecido pela própria sociedade? Esse esgarçamento do tecido social viria a ter desdobramentos na forma de lutar pela terra.

Os que ficaram a margem deste processo acabaram se fixando nas cidades. Entretanto, esta migração apenas evidenciou ainda mais a realidade da falta de ocupação formal na cidade. Com o propósito de extrair mais valia do trabalhador, ao mesmo tempo em que reduz a participação do trabalho vivo, o capital reduz a condição de exigência e de existência do trabalhador. Afinal, o capital acaba intensificando as formas de extração do sobre trabalho em tempo cada vez mais reduzido (Antunes, 1999). Algo que também não passa despercebido por Mészarós (2003), pontuando que o capital trouxe consigo uma equalização para baixo da taxa de diferencial de exploração.

Concomitante ao processo de precarização do trabalhador, sob a ótica do capitalismo, também há o componente biológico. No processo de exclusão social, o individuo em um estado de vulnerabilidade sofre a influência da patogênese do trabalho, uma vez que ao exercitar uma atividade qualquer, o ser humano está empregando num momento uma parte de sua vida nela. $O$ natural desgaste decorrente pode, em maior ou 
menor grau, modificar sua condição física e/ou psíquica. Assim a patogênese do trabalho busca compreender como o trabalho atua etiologicamente, modifica a patologia, e influencia a dinâmica do processo saúde-doença. A patogênese do trabalho é o estudo de como, de que modo o trabalho pode produzir doença ou sofrimento. (Mendes, 2007)

O que se reflete aqui se refere mais à situação onde o trabalho pode deixar de ser um prazer e se tornar algo nocivo ou perigoso para o ser humano. Situações onde pode ser até mesmo fatais, se não imediatamente, será a médio e longo prazo. A condição de nocividade ou toxicidade é inerente ao processo de trabalho adotado.

Para os catadores de produtos recicláveis, a consciência do trabalho, e seu desgaste, é aceito e bem compreendido. Mas seu desafio é conceber um modo de viver e de produção que seja preventivamente imune das circunstâncias externas ao seu espaço geográfico. Mendes (2007) aponta algumas fontes exógenas que podem interferir no assentamento como a extensão da nocividade do trabalho para o ambiente domiciliar ou familiar, para a comunidade circunvizinha e para o meio ambiente ampliado ou remoto.

Diante destas fontes, o catador de produtos recicláveis não tem como reagir isoladamente, pois há a necessidade de organização e enfrentamento, visto que no universo da produção de recicláveis, o resultado capitalista minimiza e/ou neutraliza qualquer custo que não possa ser imputado em seu processo produtivo, transferindo, assim, para a coletividade o ônus de absorver, corrigir, ou se conformar com suas decorrências diretas e indiretas. Assim, sair da precariedade e exclusão, e produzir sem riscos desnecessários, o catador de produtos recicláveis evidencia também uma luta pela saúde, que apenas está iniciando neste grupo. Pois sem ela dificilmente ele poderá usufruir de seu trabalho de forma sustentável, sem incorrer em prejuízo de seu futuro.

Como terceiro aspecto desta reflexão, procuramos perceber por uma ótica da perspectiva da organização em cooperativa dos catadores de produtos recicláveis. Ao buscar uma compreensão sobre a realidade da Cooperlix, notamos que várias autores procuraram apresentar. Cantoia (2007) abordou sobre a educação ambiental sobre os alunos e sua percepção da reciclagem de produtos, Sorbazo (2008) também centrou sua atenção à educação ambiental, aqui como práxis educativa. Silva (2009) também teve como foco de atenção a educação ambiental, sob o ponto de vista de que a Cooperlix exerce um papel de contribuição para o descarte/coleta seletiva na comunidade em geral, 
instrumentalizando o trabalho nas escolas com materiais informativos e possibilita a compreensão do processo de triagem dos resíduos na prática, por meio da visita a sua sede. Da mesma forma Henares (2006) abordou a Cooperlix pela ótica da Educação Ambiental, constatando que as ações da Cooperlix embora apresentem limitações, possibilitam a mobilização social, participação e desenvolvimento de ações de Educação Ambiental nas escolas e demais instituições.

Silva (2007), por sua vez, buscou uma compreensão mais afinada com a Cooperlix, no que tange ao cooperado averiguar a motivação que levou os parceiros e apoiadores a se envolverem com a Cooperlix; compreender o que a Cooperlix representa no imaginário dos cooperados em nível de satisfação e expectativas e analisar a trajetória profissional de cada cooperado até sua inserção como cooperado.

Outro trabalho que teve interação com a realidade da Cooperlix foi o de Ikuta (2009), a qual partiu da hipótese de que a implantação de programas de coleta seletiva com base na organização de catadores pode vir a contribuir para mudanças no modelo de gestão e gerenciamento de resíduos sólidos urbanos, ou seja, na forma de conceber, implantar e administrar os serviços neste setor. Entretanto, os resultados obtidos evidenciaram que apenas parte desta hipótese estava contemplada. Digno de nota foi a evidência de que a não estruturação de um efetivo sistema de gestão integrada de resíduos sólidos nos municípios dificulta a existência e a expansão dos programas de coleta seletiva, fragilizando as associações e cooperativas de catadores que se organizaram tendo em vista a implantação desses programas.

Takenaka (2008) centrou-se nas políticas públicas de gerenciamento de resíduos sólidos urbanos e, indiretamente, suas relações com os organismos dedicados ao processo de tratamento de resíduos sólidos, representado entre eles pela Cooperlix.

Gonçalves (2006) empreendeu um estudo sobre entender as formas de utilização / exploração do trabalho na coleta e recuperação dos resíduos sólidos recicláveis foi o principal objetivo deste trabalho. Suas percepções sobre o processo de organização dos Comitês Regionais, atuando como apoiador no Oeste Paulista, contribuem para uma compreensão da articulação organizativa dos trabalhadores catadores. Também foi interessante sua contribuição em refletir "algumas contradições da sociedade do capital 
regida por um sistema destrutivo, que muitas vezes apresenta a reciclagem de resíduos sólidos como solução".

Já pela vertente comercial da Cooperlix, temos o trabalho de Rosa (2006) onde procurou analisar as dificuldades da Cooperlix em comercializar um produto de baixo valor agregado, onde indicava que para a cooperativa pudesse agregar valor a seu produto, teria de aumentar o volume de material reciclável e procurar eliminar a figura do atravessador no negócio.

Entretanto, a gestão dos resíduos sólidos não tem merecido a atenção necessária, comprometendo a saúde da população, degradando os recursos naturais. A interdependência dos conceitos de meio ambiente, saúde e saneamento é evidente, reforçando a necessidade de integração das ações desses setores em prol da melhoria da qualidade de vida da população brasileira. Considerada um dos setores do saneamento básico, a coleta do lixo é o segmento que mais se desenvolveu dentro do sistema de limpeza urbana e o que apresenta maior abrangência de atendimento junto à população, ao mesmo tempo em que é a atividade do sistema que demanda maior percentual de recursos por parte da municipalidade. (MONTEIRO et al., 2001)

A disposição dos resíduos apresenta um agravante social, que leva pessoas a sobreviver auferindo renda da coleta de materiais recicláveis, sem organização adequada, tornando-as vulneráveis e dependentes dos esquemas de dominação impostos pelos intermediários. (LEAL, 2004)

Diante destes aspectos, temos algumas reflexões sobre a questão de que a Cooperlix, após mais de uma década de projeto, ainda não adquiriu força suficiente para se emancipar como espaço de trabalho. Esta situação leva-nos a perceber que atualmente tanto cooperativa como cooperados estão ligados a algum aspecto mais sutil, porem significativo: o grupo de apoiadores.

Nossas observações, ao longo dos últimos cinco anos, permitem identificar algumas dimensões abordadas pelo grupo de apoiadores:

1. Política: há um baixo nível de politização do cooperado, pois ainda tem pouco reconhecimento como classe. Um aspecto que chama a atenção aqui é que o catador de recicláveis atua independente dos outros, tal como um nômade, estabelecendo seu próprio modelo de relação com seus pares e com as outras pessoas. Por atuar em grupo apenas 
quando seus interesses imediatos estão ameaçados, sua articulação coletiva é mínima, tendo pouco ou nenhum poder de negociação. Com isto, ao ser inserido em uma cooperativa, oferece muita resistência em aceitar e negociar situações, submetendo-se invariavelmente numa situação de barganha por ofertas imediatistas.

2. Assistencial: Como foi capitaneado pela Secretaria Municipal de Assistência Social, os cooperados criaram uma percepção de dependência. Como visto no item anterior, o cooperado tem dificuldade de se mobilizar coletivamente, fazendo com que "ceda" esta prerrogativa para outros, dentro e fora da cooperativa. Agindo assim, ele acaba se tornando mais sensível a dependência do assistencialismo em suas diferentes formas, particularmente se ele vislumbra um viés institucionalizado.

3. Educacional: O cooperado, apesar de demonstrar interesse na educação ambiental, não quer estudar, exceto aquilo que convém para ser beneficiário. Outro componente ligado ao universo cultural imediato do indivíduo, que visa no imediatismo de sua vida soluções prontas ou que não o exijam dedicação por um longo tempo.

4. Cultural: Para o cooperado que sai do lixão, talvez o lixão não saiu do cooperado; para aquele que não veio do lixão, a impressão é que está transitoriamente se aproveitando do beneficio de ser cooperado, até que arrume algo melhor. Assim, a cooperativa acaba tendo sua eficácia prejudicada, já que não consegue atingir os fins a que se propõe junto aos cooperados. Há um comportamento latente tanto da sociedade como do cooperado de que possa haver uma meia consciência ambiental.

5. Econômica: O cooperado vê no grupo de apoiadores uma fonte de custeio e de solução dos problemas econômicos da cooperativa e deles próprios. Derivado do comportamento de se limitar a viver a vida um dia de cada vez, pois alguns têm em sua história pessoal situações limite, o cooperado acaba se apropriando do que tem no dia para viver, se não tem no dia seguinte é outro dia, distante. Assim, há uma transferência de responsabilidade (dele) para a liderança da cooperativa (seus pares), que por sua vez acabam se amparando em uma instância superior (ou maior que a cooperativa), na forma do poder público e/ou do grupo de apoiadores.

Este perfil traçado impõe uma incapacidade de emancipação a partir das relações de trabalho da própria atuação da cooperativa, visto que a precarização do trabalho do coletor de reciclados / cooperado é um assunto ainda não resolvido. 


\section{CONSIDERAÇOES FINAIS}

Diante do exposto, acreditamos que os desafios de se trabalhar as pessoas, retirando de uma situação de vida e colocando em outra, não significa que problemas subjacentes estejam assim resolvidos. As organizações públicas, privadas ou do terceiro setor são impotentes quando a questão está residindo no âmbito das pessoas. As pessoas é que são chave no processo de utilizar as instituições de forma a promover a melhora nas condições de vida e de trabalho dos outros.

Mas as organizações precisam de pessoas e do trabalho que elas proporcionam. Numa sociedade cada vez mais complexa é preciso que as pessoas que ocupem posições chave nas suas respectivas instituições proporcionem os meios ao seu alcance, a fim de propiciar a outros uma melhora em suas condições de vida pessoal e profissional.

Longe de utópico, a necessidade de se mapear os elementos que proporcionem, conservem, aumentem ou modifiquem a precarização do trabalhador deve ser uma constante na matriz de gestão de um grupo de apoiadores, pois as pessoas objeto de reinserção no processo produtivo precisam de serem acompanhadas em seu processo de transformação pessoal e social.

Não fazer isto, acarreta riscos ao sucesso na implementação de projetos de forma duradoura, visto que o individuo traz consigo um repertório, o qual pode afetar sua própria transformação.

\section{REFERÊNCIAS BIBLIOGRÁFICAS}

ANTUNES, R., Os Sentidos do Trabalho. São Paulo: Boitempo, 1999.

CANTÓIA, S.F. Educação Ambiental e Coleta Seletiva em Presidente PrudenteSp:avaliando seus resultados no Conjunto Habitacional Ana Jacinta. Presidente Prudente: FCT, UNESP, 2007. Dissertação (mestrado) - Faculdade de Ciências e Tecnologia, Universidade Estadual Paulista, 2007.

GILSTER, P. Digital literacy. New York: Wiley Computer Publishing, 1997. 
GONÇALVES, M.A. O Trabalho no Lixo. Presidente Prudente: FCT, UNESP, 2005. $307 \mathrm{f}$. Tese (Doutorado) - Faculdade de Ciências e Tecnologia, Universidade Estadual Paulista, 2006.

HENARES, E. L. Educação Ambiental e Resíduos Sólidos: a Ação da Cooperlix em Presidente Prudente-SP Presidente Prudente: 2006. Dissertação (mestrado) Faculdade de Ciências e Tecnologia, Universidade Estadual Paulista.

IKUTA, F. A. Resíduos sólidos urbanos no Pontal do Paranapanema - São Paulo: inovação e desafios na coleta seletiva e organização de catadores. Presidente Prudente: FCT, UNESP, 2009. Tese (Doutorado) - Faculdade de Ciências e Tecnologia, Universidade Estadual Paulista, 2009.

KOTKIN, J. The city: a global history. Modern Library Edition, New York, 2005.

KOTKIN, J. The new geography: how the digital revolution is reshaping the american landscape. Random House, New York, 2001.

KOTKIN, J. The next hundred million: America in 2050. The Penguin Press, New York, 2010.

LEAL, A. C, et all. Resíduos Sólidos no Pontal do Paranapanema. Presidente Prudente: Antonio Thomaz Júnior, 2004.

MARX, K., O Capital. São Paulo: Edigraf, 1958

MENDES, R., Patologia do Trabalho. 2ed. São Paulo: Atheneu, 2007.

MÉSZARÓS, I., O Século XXI: socialismo ou barbárie? São Paulo: Boitempo, 2003

MONTEIRO, J. H. P. . [et al.] Manual de Gerenciamento Integrado de resíduos sólidos. Coordenação técnica Victor Zular Zveibil. Rio de Janeiro: IBAM, 2001.

ROSA, C. P. As Cooperativas de Catadores de Resíduos Sólidos: um estudo sobre as dificuldades de comercialização dos produtos na Cooperlix. In: ARANA, A. R. A. (Org.). Cooperativismo: uma alternativa de gestão. Presidente Prudente: Macromídia, 2006. p. 21-43.

SILVA, A. P. da. Educação ambiental em resíduos sólidos nas unidades escolares municipais de Presidente Prudente-SP. Presidente Prudente : 2009, 207f. Dissertação (mestrado) - Universidade Estadual Paulista, Faculdade de Ciências e Tecnologia

SILVA, J. J. Cooperativismo e Redes Sociais: A Organização do Trabalho na Cooperlix de Presidente Prudente. Presidente Prudente: FCT, UNESP, 2007. 193 f. Tese (doutorado) - Faculdade de Ciências e Tecnologia, Universidade Estadual Paulista, 2007. 
SOBARZO, L.C. D. Resíduos Sólidos: do conhecimento científico ao saber curricular - a releitura do tema em livros didáticos de Geografia. Presidente Prudente : 2008, 284 f. Tese (doutorado) - Universidade Estadual Paulista, Faculdade de Ciências e Tecnologia

TAKENAKA, E. M. M. Políticas Públicas de Gerenciamento Integrado de Resíduos Sólidos Urbanos no Município de Presidente Prudente-SP, Presidente Prudente: FCT, UNESP, 2008, 232f. Tese (Doutorado) - Faculdade de Ciências e Tecnologia, Universidade Estadual Paulista, 2008.

VASAPOLLO, L. O Trabalho Atípico e a Precariedade: elemento estratégico determinante do capital no paradigma pós-fordista. In: ANTUNES, R. (Org.). Riqueza e Miséria do Trabalho no Brasil. São Paulo: Boitempo, 2006. p. 45-57. 